\title{
Light stability of the isolated CP43 studied by infrared and terahertz spectroscopy
}

\author{
Y.G. QU ${ }^{*, *,+}$, X.L. WANG ${ }^{* * *+}$, and T.Y. KUANG ${ }^{* *}$ \\ College of Life Sciences, Linyi University, 276000 Linyi, China* \\ Key Laboratory of Photobiology, Institute of Botany, Chinese Academy of Sciences, 100093 Beijing, China** \\ College of Life Sciences, Shandong Agricultural University, 271018 Taian, China ${ }^{* * *}$
}

\begin{abstract}
Here, the light-induced changes of the core antenna complex chlorophyll protein 43 (CP43) isolated from PSII of spinach were assessed using infrared and terahertz $(\mathrm{THz})$ spectroscopy. We found that the collective vibrational modes at low frequencies and the secondary structures of CP43 were altered upon illumination. The helix changed more than any other secondary structure. CP43 is more easily damaged by illumination than PSII. Infrared and THz spectroscopy have different functions in protein studies. THz spectroscopy has potential in evaluating the stability of proteins.
\end{abstract}

Additional key words: amide I band; conformation; degradation; photoinhibition.

\section{Introduction}

The photosynthetic proteins CP43 and CP47 in PSII form an internal antenna system. The CP43 and CP47 harvest light and transfer excitons to PSII reaction centers (Barber et al. 2000, Bricker and Frankel 2002). CP43 complexes interact with the reaction centers at $\mathrm{D}_{1}$ positions and interact with 13 chlorophyll (Chl) $a$ pigments and three $\beta$-carotenes as shown by crystallographic data (Guskov et al. 2009, Umena et al. 2011, Hall et al. 2016). $\mathrm{D}_{1}$ and CP43 provide ligands to the inorganic $\mathrm{Mn}_{4} \mathrm{CaO}_{5}$ center that are required for the oxidation of $\mathrm{H}_{2} \mathrm{O}$ (Liu et al. 2011).

Upon high light illumination, the pigments in the PSII membrane suffered by impairment (Telfer et al. 1991, Bumann and Oesterhelt 1995), proteins such as $\mathrm{D}_{1}$ were degraded and photosynthetic activity was lost (Aro et al. 1990, Shipton and Barber 1991, Pokorska and Romanowska 2007). CP43 and CP47 in PSII membrane were damaged during strong illumination (Salter et al. 1992). When PSII membranes from spinach were subjected to light of $5,000 \mu \mathrm{mol}$ (photon) $\mathrm{m}^{-2} \mathrm{~s}^{-1}$ to an aerobic environment, the degradation of both $\mathrm{D}_{1}$ and $\mathrm{D}_{2}$ proteins occurred. CP43 was similarly degraded to three products of low molecular mass (Yamamoto and Akasaka 1995). CP43 was lost when PSII membranes were illuminated upon alkaline Tris treatment. This loss of CP43 occurred due to its crosslinking with CP47 and $\mathrm{D}_{1}$ (Mori et al. 1995). In these researches, CP43 is in the interior of PSII. A study on the isolated CP43 would be more significant because it can delete the effects of other components in PSII.

Terahertz $(\mathrm{THz})$ radiation ranges from 0.1 to $10 \mathrm{THz}$ which is between far infrared and microwave rays on the electromagnetic spectrum. It bridges the gap between electronics and photonics and exhibits unique properties (Chen et al. 2013). Biomolecules exhibit collective vibrational modes in the $\mathrm{THz}$ range (Yoneyama et al. 2008). $\mathrm{THz}$ spectroscopy can provide information on both phase and amplitude, so it can be used to study the collective vibrational modes of biomolecules (Tani et al. 1997, Zhou et al. 2019). THz spectroscopy can accurately measure the flexibility of proteins and can differentiate between proteins, conformations, and wild type vs. mutants (Markelz et al. 2002, Mernea et al. 2015). $\mathrm{THz}$ spectroscopy has seldom been used on the study of photosynthetic membrane proteins.

In order to further investigate the light-induced changes of the isolated CP43 and photoinhibition mechanism, infrared spectroscopy, SDS-PAGE, and THz spectroscopy were used in this study. The results showed that the collective vibrational modes at low frequencies and the secondary structure of CP43 changed upon illumination. CP43 is more easily damaged by illumination than PSII is. The structure damage and degradation of CP43 should be related to the photoinhibition. THz spectroscopy is a good complement to the study of photosynthetic membrane proteins.

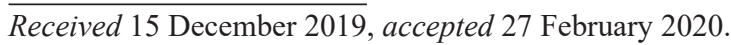

${ }^{+}$Corresponding author; email: quyuangang@163.com, xlwang@sdau.edu.cn

Abbreviations: CP43 - chlorophyll protein 43; CP47 - chlorophyll protein 47; DM - L-dodecyl maltoside; FT-IR - Fourier transformationinfrared; MES - 2-(N-morphine) ethanesulfonic acid; SDS-PAGE - sodium dodecyl sulfate-polyacrylamide gel electrophoresis; $\mathrm{THz}$ - terahertz; THz-TDS - terahertz time-domain spectroscopy.

Acknowledgements: This work was supported by Shandong Provincial Natural Science Foundation, China (ZR2017MC010) and the Scientific Research Foundation for the Returned Overseas Chinese Scholars, State Education Ministry, China (the $47^{\text {th }}$ batch). 


\section{Materials and methods}

CP43 purification: Spinach (Spinacia oleracea L.) was grown in half Hoagland solution under conditions of controlled light $\left[400 \mu \mathrm{mol}\right.$ (photon) $\mathrm{m}^{-2} \mathrm{~s}^{-1}$, 12-h photoperiod], temperature $\left(27^{\circ} \mathrm{C}\right.$ light, $18^{\circ} \mathrm{C}$ dark $)$ and humidity $(60 \%)$. PSII particles were isolated from spinach according to Kuwabara and Murata (1982). Core complexes were extracted as described by Ghanotakis et al. (1989). The purification of CP43 followed the protocols of Shan et al. (2001). The core complexes were first treated with $0.8 \mathrm{~mol} \mathrm{~L}^{-1}$ Tris buffer ( $\mathrm{pH} 8.0$ ) for $15 \mathrm{~min}$ to a final $\mathrm{Chl}$ concentration of $0.1 \mathrm{mg} \mathrm{mL}^{-1}$ and centrifuged at $40,000 \times \mathrm{g}$ for $10 \mathrm{~min}$. The procedure was performed twice to remove completely the $33 \mathrm{kDa}$ extrinsic protein. The pellet was resuspended in $50 \mathrm{mmol} \mathrm{L}^{-1} 2$-(N-morphine) ethanesulfonic acid (MES) (Sigma-Aldrich, USA), $150 \mathrm{mmol} \mathrm{L}^{-1}$ $\mathrm{NaCl}$, and $400 \mathrm{mmol} \mathrm{L^{-1 }}$ sucrose $(\mathrm{pH}$ 6.0) at Chl concentration of $1.5 \mathrm{mg} \mathrm{mL}^{-1}$, and incubated with an equal volume of $20 \mathrm{mmol} \mathrm{L}^{-1}$ Bis-Tris, $4 \mathrm{~mol} \mathrm{~mL}^{-1} \mathrm{LiClO}_{4}$, and $15 \%$ L-dodecyl maltoside (DM) (Sigma-Aldrich, USA) buffer (pH 6.0) for $20 \mathrm{mmol} \mathrm{L}^{-1}$ Bis-Tris (pH 6.0) for $2 \mathrm{~h}$ and then loaded onto a DEAE-Fractogel TSK 650S anionexchange column $(1.6 \times 12 \mathrm{~cm})$ that was equilibrated with $20 \mathrm{mmol} \mathrm{L}^{-1}$ Bis-Tris and $0.05 \% \mathrm{DM}(\mathrm{pH} 6.0)$ at a flow rate of $0.5 \mathrm{ml} \mathrm{min}{ }^{-1}$. CP43 was the first fraction that did not bind to the column and was eluted. The preparations were stored at $-196^{\circ} \mathrm{C}$. All of the above procedures were performed at $4^{\circ} \mathrm{C}$ in the dark.

White light illumination: The light treatment of 5,000 $\mu$ mol(photon) $\mathrm{m}^{-2} \mathrm{~s}^{-1}$ was conducted with a halogen lamp (CDD-1000, Bela Design, China), which shows an emission of 260-2,500 nm and an emission of 400-760 nm in the visible light range. Light was filtered through a flat glass bottle containing $\mathrm{CuSO}_{4}$ solution to absorb heat from the light source. The CP43 sample was placed in a vessel, the temperature of which was controlled by circulating cold water. The concentration of the CP43 sample was $0.2 \mathrm{mg}(\mathrm{Chl} a) \mathrm{mL}^{-1}$. During the light treatment, the sample was stirred continually.

Sodium dodecyl sulfate-polyacrylamide gel electrophoresis (SDS-PAGE): The SDS-PAGE was performed as described by Qu et al. (2007). The polyacrylamide concentrations of the separation and stacking gels were 15 and $4 \%$, respectively. The gel was stained with Coomassie Brilliant Blue R-250.

Fourier transformed-infrared (FT-IR) spectroscopy: $\mathrm{CP} 43$ or PSII samples were washed in $\mathrm{D}_{2} \mathrm{O}$, and the sample concentration was approximately $2 \mathrm{~g}(\mathrm{Chl} a) \mathrm{L}^{-1}$. For FT-IR measurements, the sample was first dripped on a $\mathrm{CaF}_{2}$ disk and then dried into a semi-hydrated film in a vacuum. Spectra were obtained using a FT-IR spectrometer (Nicolet Magna 550 Series II, Midac Co., USA). Data treatment and band decomposition of the original amide I have been described by Taneva et al. (1995).
Terahertz time-domain spectroscopy (THz-TDS): Concentration of the CP43 sample used was $2 \mathrm{~g}(\mathrm{Chl} a)$ $\mathrm{L}^{-1}$. Samples of $50 \mu \mathrm{l}$ were mixed with approximately 88 $\mathrm{mg}$ of spectrophotometric-grade polyethylene powder, which is close to transparent in the $\mathrm{THz}$ region. Mixtures were then pressed into disks of $\sim 1.5 \mathrm{~mm}$ in thickness and $10 \mathrm{~mm}$ in diameter. A vacuum cell was used to delete the water vapor signal. For each measurement, data from the polyethylene powder instead of the CP43 sample were used as a reference waveform.

THz-TDS measurements were employed (Shi and Wang 2005). A mode-locked Ti:sapphire laser (Mai Tai, Spectra Physics, USA) was used to generate THz radiation from a piece of GaAs (110) wafer by optical rectification. $\mathrm{THz}$ waves were passed through samples and directed onto ZnTe (110) crystals for electrooptical sampling. All the acquired samples and reference waveforms were converted to their Fourier transforms $E_{\mathrm{r}}(\omega)$ and $E_{\mathrm{s}}(\omega) . E_{\mathrm{r}}(\omega)$ is the electrical field strengths of the signal passing through an empty aperture and $E_{\mathrm{s}}(\omega)$ is that propagating through the sample. The transmission spectra were obtained from the $E_{\mathrm{s}}(\omega) / E_{\mathrm{r}}(\omega)$ ratio.

Statistical analysis: All experiments were repeated at least three times. The relative changes [\%] of $\alpha$-helix or $\beta$-sheet are expressed as mean \pm standard deviation (SD). The analyses were done with SPSS 20.0 (IBM, Chicago, USA).

\section{Results}

Infrared spectra of CP43: The secondary structures of membrane proteins can be determined successfully using infrared spectroscopy. The vibration of amide I at $1,700-1,600 \mathrm{~cm}^{-1}$ occurs due to $\mathrm{C}=\mathrm{O}$ vibrations in the polypeptide, and the frequency of which changes according to $\mathrm{H}$ bonding and transition dipole coupling, both of which can be used to study protein structure (De Las Rivas and Barber 1997, Hutchison et al. 1998, Hu et al. 2005).

The secondary structures could be identified through assessment of the overlapping sub-bands in the amide I region via second derivative analysis. Fig. $1 B$ shows that the peak at $1,655 \mathrm{~cm}^{-1}$ is mediated by the $\alpha$-helix, whilst the peaks at 1,637 and $1,626 \mathrm{~cm}^{-1}$ are due to the $\beta$-sheet (De Las Rivas and Barber 1997). Fig. $1 A$ shows that the FT-IR spectra of CP43 changed under illumination. In order to more distinctly present the changes of secondary structures, absorption difference spectra for the amide I band were obtained (Fig. $1 C$ ). It shows that, under illumination, the $\alpha$-helix content decreased with time, while the $\beta$-sheet content began increasing slightly from $5 \mathrm{~min}$. Fig. 1 also indicates that the helix changed more than any other secondary structure. The percentage contents of CP43 secondary structures were obtained via Fourier deconvolution. The helix contents of CP43 decreased more than that of PSII, and the $\beta$-sheet contents of CP43 increased more than that of PSII when illuminated for the same time (Fig. 2). It implies that CP43 is more easily damaged by illumination than the PSII complex. 

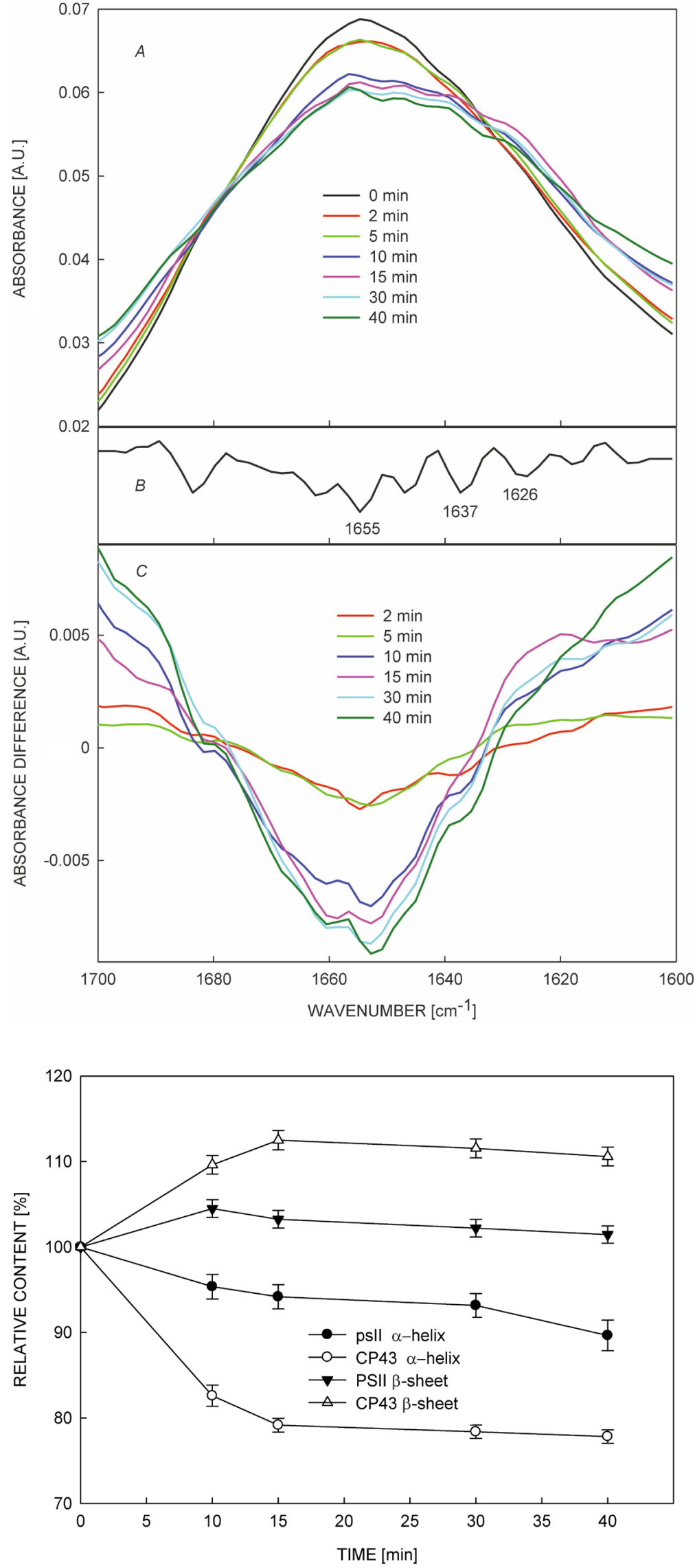

Fig. 1. Infrared absorption spectra of chlorophyll protein 43 (CP43). (A) Fourier transform-infrared (FT-IR) spectra of the amide I $\left(1,700-1,600 \mathrm{~cm}^{-1}\right)$ band of $\mathrm{CP} 43$ in $\mathrm{D}_{2} \mathrm{O}$ following normalization when illuminated at 5,000 $\mu \mathrm{mol}$ (photon) $\mathrm{m}^{-2} \mathrm{~s}^{-1}$. (B) Second derivative of the amide I band of CP43 measured in $\mathrm{D}_{2} \mathrm{O}$. (C) Absorption difference spectra of the amide I band (the infrared spectra of illuminated samples minus that of control sample at 0 min of illumination after area normalization).

Fig. 2. Relative changes [\%] of the $\alpha$-helix and $\beta$-sheet content in PSII and chlorophyll protein 43 (CP43) with illumination time. Relative changes $[\%]=$ $\mathrm{C}_{\mathrm{t}} \times \mathrm{C}_{\mathrm{n}} \times 100 . \mathrm{C}_{\mathrm{t}}$ is the $\alpha$-helix or $\beta$-sheet percentage content for the treated samples, and $\mathrm{C}_{\mathrm{n}}$ is the $\alpha$-helix or $\beta$-sheet percentage content for the native sample. The data represented were mean values \pm standard deviations from three experiments. 
In addition, as seen in Fig. 1, the decreased extent of the CP43 helix content was really greater than the increased extent of the $\beta$-sheet content.

Degradation of CP43: The SDS-PAGE results indicated that CP43 apparently did not change when illuminated for $10 \mathrm{~min}$ (Fig. 3). At $30 \mathrm{~min}$, it began to degrade, and it degraded most at $60 \mathrm{~min}$. When CP43 degraded, no new bands appeared below the band of CP43 itself, implying that the degradation of $\mathrm{CP} 43$ was nonspecific. The various peptides resulting from the degradation were not enough to be visible on the gel or left the gel completely.

THz spectra of CP43: The response time of CP43 was slower than that of polyethylene (Fig. 4). The response time of the illuminated samples was shorter than that of

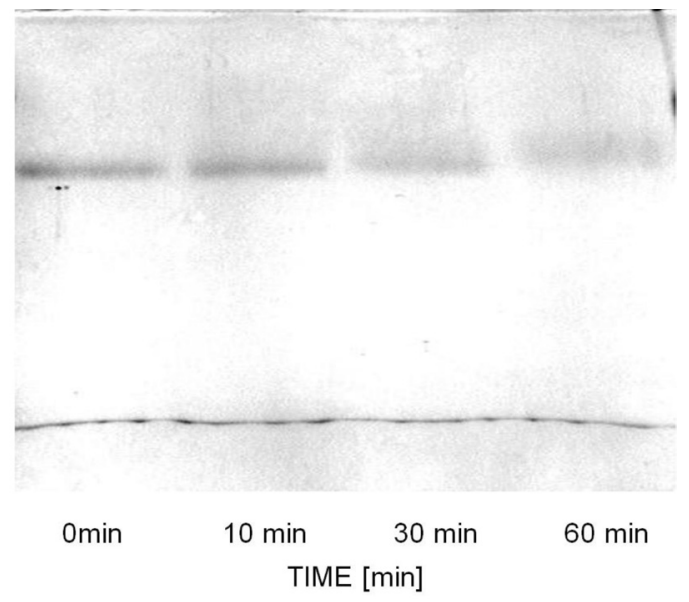

Fig. 3. Effects of illumination on the degradation of chlorophyll protein 43 (CP43). CP43 samples were illuminated in white light at 5,000 $\mu \mathrm{mol}$ (photon) $\mathrm{m}^{-2} \mathrm{~s}^{-1}$ for 10,30 , and $60 \mathrm{~min}$, respectively. the intact one, and it was the shortest when illuminated for $30 \mathrm{~min}$.

The time-domain $\mathrm{THz}$ waveforms shown in Fig. 4 were further transitioned into frequency-domain amplitudes (transmission spectra) using fast Fourier transform (Fig. 5). The transmission spectrum of CP43 showed no major changes upon illumination for $5 \mathrm{~min}$. Under illumination for 10 and $30 \mathrm{~min}$, the left half of the spectrum shifted to a lower frequency, and a peak at $1.81 \mathrm{THz}$ appeared.

The absorbance of the samples is given by $E_{\mathrm{s}}(\omega) / E_{\mathrm{r}}(\omega)=$ $T(\omega) \exp [-\alpha d+i(n \omega d / c)]$, where $T(\omega)$ is the loss of reflection on sample surface, $n$ is the sample index, $c$ is the speed of light in vacuum, $d$ is the sample thickness, $\alpha$ is the power absorption coefficient, and $\alpha d$ represents the absorption of the sample. For 5 min of illumination, the absorption spectra were close to the intact curve, only with intensity being lower than that of the intact curve between 1.2 and $2.1 \mathrm{THz}$ (Fig. 6). After $10 \mathrm{~min}$ of illumination, the spectra changed much more than the intact curve. Between 0 and $1.0 \mathrm{THz}$, the curve presented an increasing trend with increasing frequency, and the absorbance intensity was lower than that of the intact curve. Between 2.0 and $2.3 \mathrm{THz}$, a peak at $2.18 \mathrm{THz}$ appeared, instead of the decreasing trend for the intact curve. On the whole, the absorbance of CP43 at $10 \mathrm{~min}$ became lower at low frequency and higher at high frequency than that of the intact curve, presenting an increasing trend. The spectra for 30 min of illumination showed no major changes relative to the spectra obtained after 10 min of illumination.

The dynamics of conformations happens over picosecond intervals, and that leads to collective vibrational mode changes which can be measured under $\mathrm{THz}$ frequencies (Markelz et al. 2002). In this study, the THz timedomain waveforms, transmission and absorbance spectra of CP43 all changed, which indicates that the collective vibrational mode of CP43 changed upon illumination and implies that $\mathrm{THz}$ spectroscopy has potential in evaluating the stability of proteins.

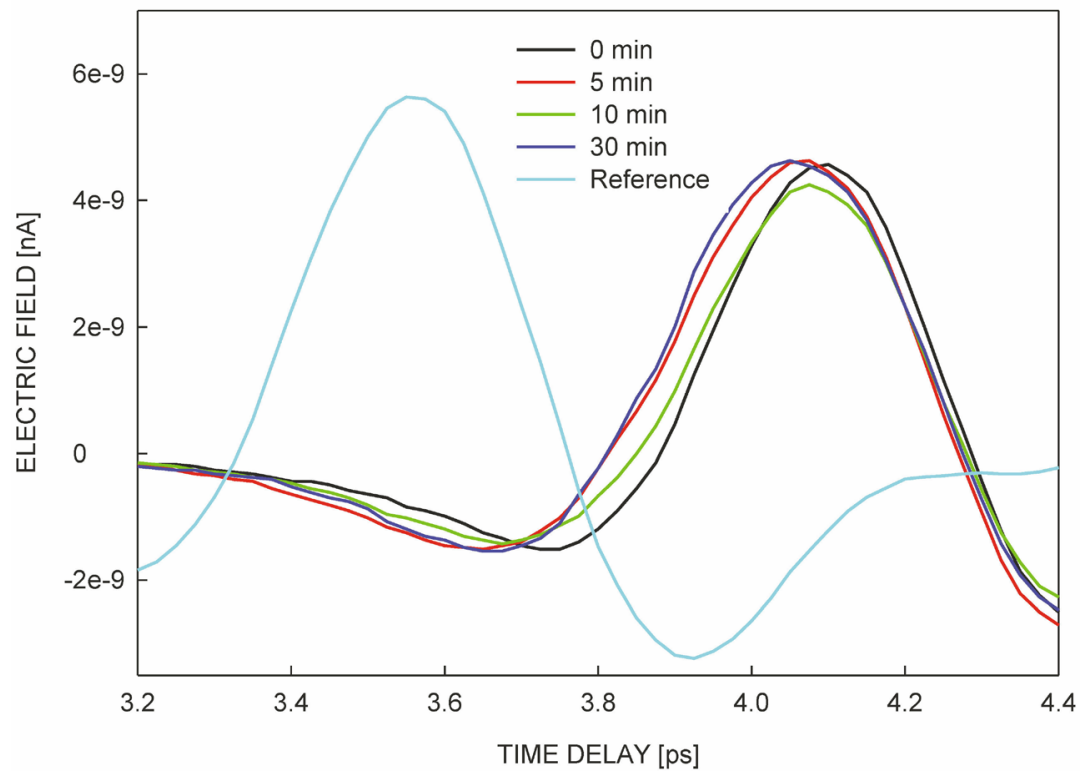

Fig. 4. The time-domain terahertz $(\mathrm{THz})$ waveforms of chlorophyll protein 43 (CP43). Illumination intensity was at 5,000 $\mu$ mol(photon) $\mathrm{m}^{-2} \mathrm{~s}^{-1}$. Illumination times were $0,5,10$, and $30 \mathrm{~min}$, respectively. Reference curve was obtained from polyethylene. 

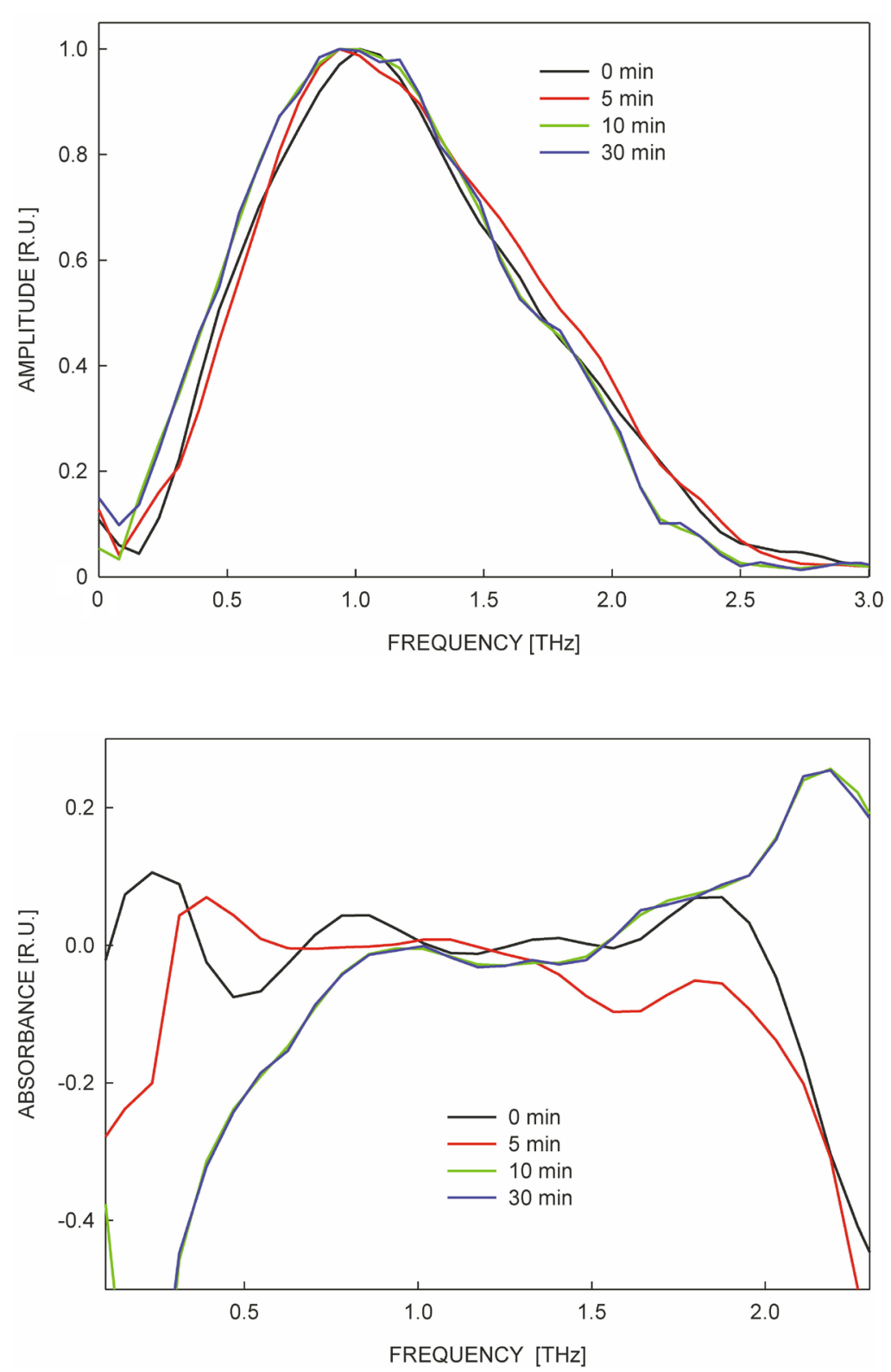

Fig. 5. Terahertz $(\mathrm{THz})$ transmission spectra of chlorophyll protein 43 (CP43). The light intensity and illumination time are shown in Fig. 4. Reference curve was obtained from polyethylene.
Fig. 6. Terahertz (THz) absorption spectra of chlorophyll protein 43 (CP43). The light intensity and illumination time are shown in Fig. 4.

\section{Discussion}

It is known that structure of the general protein, especially the nonphotosynthetic protein, is stable against high light. However, the results here showed that CP43, as a photosynthetic core antenna protein, is sensitive to high illumination (Figs. 1-3).

This occurs because of the association of proteins, lipids, and pigments with ${ }^{1} \mathrm{O}_{2} \cdot{ }^{1} \mathrm{O}_{2}$ causes destruction, degradation, and pigment bleaching of PSII and its components, highlighting its importance in the attenuated PSII activity (Ohad et al. 1992, Aro et al. 1993, Andersson and Aro 2001, Krieger-Liszkay 2004). The formation of ${ }^{1} \mathrm{O}_{2}$ occurs due to triplet-triplet energy transfer from triplet $\mathrm{Chl}$ or triple carbonyl to $\mathrm{O}_{2}$, which happens both in the PSII antenna and reaction center. In the PSII antenna complex, triple $\mathrm{Chl}$ is formed through photosensitization
(Pospíšil 2016).

Additionally, the carotene in CP43 has the capability to quench triplet $\mathrm{Chl}$. To maintain an effective quenching effect, $\beta$-carotene must be properly distanced and oriented from Chls (Pospíśil 2016). Under strong illumination, structural changes to $\mathrm{CP} 43$ change the distance and orientation between $\mathrm{Chl} a$ and $\beta$-carotene, and then decrease the quenching effect and increase the ${ }^{1} \mathrm{O}_{2}$ formation.

For green higher plants, excessive energy can be dissipated as heat by the reported xanthophyll cycle. The xanthophyll in PSII possesses the lowest singlet excited state, below that of ${ }^{1} \mathrm{Chl}^{*}$ (Frank et al. 2000, Müller et al. 2001). Therefore, it may directly deexcite ${ }^{1} \mathrm{Chl}{ }^{*}$ and decrease the production of ${ }^{1} \mathrm{O}_{2}$. However, there are no xanthophylls in CP43, and this results in the greater sensitivity to illumination than that of PSII (Fig. 2).

Photoinhibition of PSII is a phenomenon that occurs 
in all oxygenic photosynthetic organisms under high irradiance (Ohad et al. 1992). Despite light being the driving force of PSII, high light additionally switches off electron transport and destroys PSII structures (Aro et al. 1993). Although photoinhibition has been studied for a long time, there is no consensus regarding its mechanism. Upon illumination, the structure damage and degradation of CP43 should be related to the photoinhibition.

Low-frequency modes are associated with the collective motion of the biomolecules. The results presented here show that the changing trend of infrared spectra is not always in agreement with that of $\mathrm{THz}$ spectra. $\mathrm{THz}$ spectra are complex and difficult to interpret, and the secondary structure of proteins is not as amenable to analysis by this approach. Infrared and $\mathrm{THz}$ spectroscopy have different functions in the study of proteins. The infrared amide I band in the 1,700-1,600 $\mathrm{cm}^{-1}$ region can characterize secondary structures, whilst $\mathrm{THz}$ spectroscopy is appropriate for the visualization of protein collective vibrational modes. In addition, the photosynthetic proteins usually contain pigments, which are easily bleached by visible light, while $\mathrm{THz}$ radiation is located from 0.1 to $10 \mathrm{THz}$ and has no such photobleaching effects. Therefore, THz spectroscopy is indeed a good complement to the study on photosynthetic membrane proteins.

Under illumination, the $\mathrm{THz}$ absorbance spectrum of CP43 shows an increasing trend compared with that of the intact curve (Fig. 6B). Can this increasing trend be considered an indicator of the denaturation of biological molecules? It remains to be studied further.

\section{References}

Andersson B., Aro E.M.: Photodamage and $\mathrm{D}_{1}$ protein turnover in photosystem II. - In: Aro E.M., Andersson B. (ed.): Regulation of Photosynthesis. Pp. 377-393. Springer, Dordrecht 2001.

Aro E.M., Hundal T., Carlberg I., Andersson B.: In vitro studies on light-induced inhibition of photosystem II and $\mathrm{D}_{1}$-protein degradation at low temperatures. - BBA-Bioenergetics 1019: 269-275, 1990.

Aro E.M., Virgin I., Andersson B.: Photoinhibition of photosystem II. Inactivation, protein damage and turnover. - BBABioenergetics 1143: 113-134, 1993.

Barber J., Morris E., Büchel C.: Revealing the structure of the photosystem II chlorophyll binding proteins, CP43 and CP47.BBA-Bioenergetics 1459: 239-247, 2000

Bricker T.M., Frankel L.K.: The structure and function of CP47 and CP43 in Photosystem II. - Photosynth. Res. 72: 131, 2002.

Bumann D., Oesterhelt D.: Destruction of a single chlorophyll is correlated with the photoinhibition of photosystem II with a transiently inactive donor side. - P. Natl. Acad. Sci. USA 92: 12195-12199, 1995.

Chen T., Li Z., Mo W.: Identification of biomolecules by terahertz spectroscopy and fuzzy pattern recognition. - Spectrochim. Acta A 106: 48-53, 2013.

De Las Rivas J., Barber J.: Structure and thermal stability of photosystem II reaction centers studied by infrared spectroscopy. - Biochemistry-US 36: 8897-8903, 1997.

Frank H.A., Bautista J.A., Josue J.S., Young A.J.: Mechanism of non-photochemical quenching in green plants: energies of the lowest excited singlet states of violaxanthin and zeaxanthin. -
Biochemistry-US 39: 2831-2837, 2000.

Ghanotakis D.F., de Paula J.C., Demetriou D.M. et al.: Isolation and characterization of the $47 \mathrm{kDa}$ protein and the D1-D2cytochrome $b-559$ complex. - BBA-Bioenergetics 974: 44-53, 1989.

Guskov A., Kern J., Gabdulkhakov A. et al.: Cyanobacterial photosystem II at $2.9-\AA$ resolution and the role of quinones, lipids, channels and chloride. - Nat. Struct. Mol. Biol. 16: 334-342, 2009.

Hall J., Renger T., Picorel R., Krausz E.: Circularly polarized luminescence spectroscopy reveals low-energy excited states and dynamic localization of vibronic transitions in CP43. BBA-Bioenergetics 1857: 115-128, 2016.

$\mathrm{Hu}$ Z.H., Xu Y.N., Gong Y.D., Kuang T.G: Effects of heat treatment on the protein secondary structure and pigment microenvironment in photosystem 1 complex. Photosynthetica 43: 529-534, 2005.

Hutchison R.S., Betts S.D., Yocum C.F., Barry B.A.: Conformational changes in the extrinsic manganese stabilizing protein can occur upon binding to the photosystem II reaction center: An isotope editing and FT-IR study. - BiochemistryUS 37: 5643-5653, 1998

Krieger-Liszkay A.: Singlet oxygen production in photosynthesis. - J. Exp. Bot. 56: 337-346, 2004

Kuwabara T., Murata N.: Inactivation of photosynthetic oxygen evolution and concomitant release of three polypeptides in the photosystem II particles of spinach chloroplasts. - Plant Cell Physiol. 23: 533-539, 1982.

Liu H.J., Huang R.Y., Chen J. et al.: Psb27, a transiently associated protein, binds to the chlorophyll binding protein CP43 in photosystem II assembly intermediates. - P. Natl. Acad. Sci. USA 108: 18536-18541, 2011.

Markelz A.G., Whitmire S., Hillebrecht J., Birge R.: THz time domain spectroscopy of biomolecular conformational modes. - Phys. Med. Biol. 47: 3797-3805, 2002.

Mernea M., Ionescu A., Vasile I. et al:: In vitro human serum albumin glycation monitored by terahertz spectroscopy. Opt. Quant. Electron. 47: 961-973, 2015.

Moil H., Yamashita Y., Akasaka T., Yamamoto Y.: Further characterization of the loss of antenna chlorophyll-binding protein CP43 from photosystem II during donor-side photoinhibition. - BBA-Bioenergetics 1228: 37-42, 1995.

Müller P., Li X.P., Niyogi K.K.: Non-photochemical quenching. A response to excess light energy. - Plant Physiol. 125: 15581566, 2001.

Ohad I., Prášil O., Adir N.: Dynamics of photosystem II: Mechanism of photoinhibition and recovery process. - In: J. Barber (ed.): The Photosystems: Structure, Function and Molecular Biology. Pp. 295-348. Elsevier, Amsterdam 1992.

Pokorska B., Romanowska E.: Photoinhibition and $\mathrm{D}_{1}$ protein degradation in mesophyll and agranal bundle sheath thylakoids of maize. - Funct. Plant Biol. 34: 844-852, 2007.

Pospíšil P.: Production of reactive oxygen species by photosystem II as a response to light and temperature stress - Front. Plant Sci. 7: 1950, 2016.

Qu Y.G., Qin X.C., Wang W.F. et al.: Energy transfer of aromatic amino acids in photosystem 2 core antenna complexes CP43 and CP47. - Photosynthetica 45: 266-271, 2007.

Salter A.H., Virgin I., Hagman A., Andersson B.: On the molecular mechanism of light-induced $\mathrm{D}_{1}$ protein degradation in photosystem II core particles. - Biochemistry-US 31: 3990-3998, 1992.

Shan J.X., Wang J.S., Ruan X. et al.: Changes of absorption spectra during heat-induced denaturation of Photosystem II core antenna complexes CP43 and CP47: revealing the binding states of chlorophyll molecules in these two complexes. - 
BBA-Bioenergetics 1504: 396-408, 2001.

Shi Y.L., Wang L.: Collective vibrational spectra of $\alpha$ - and $\gamma$-glycine studied by terahertz and Raman spectroscopy. J. Phys. D Appl. Phys. 38: 3741-3745, 2005.

Shipton C.A., Barber J.: Photoinduced degradation of the $\mathrm{D}_{1}$ polypeptide in isolated reaction centers of photosystem II: evidence for an autoproteolytic process triggered by the oxidizing side of the photosystem. - P. Natl. Acad. Sci. USA 88: 6691-6695, 1991.

Taneva S.G., Caaveiro J.M.M., Muga A., Goñi F.M.: A pathway for the thermal destabilization of bacteriorhodopsin. - FEBS Lett. 367: 297-300, 1995.

Tani M., Matsuura S., Sakai K., Nakashima S.: Emission characteristics of photoconductive antennas based on lowtemperature-grown GaAs and semi-insulating GaAs. - Appl. Optics 36: 7853-7859, 1997.

Telfer A., De Las Rivas J., Barber J.: $\beta$-Carotene within the isolated photosystem II reaction center: photooxidation and irreversible bleaching of this chromophore by oxidized P680.BBA-Bioenergetics 1060: 106-114, 1991.

Umena Y., Kawakami K., Shen J.R., Kamiya N.: Crystal structure of oxygen-evolving photosystem II at a resolution of $1.9 \AA$. Nature 473: 55-60, 2011.

Yamamoto Y., Akasaka T.: Degradation of antenna chlorophyllbinding protein $\mathrm{CP} 43$ during photoinhibition of photosystem II. - Biochemistry-US 34: 9038-9045, 1995.

Yoneyama H., Yamashita M., Kasai S. et al.: Terahertz spectroscopy of native-conformation and thermally denatured bovine serum albumin (BSA). - Phys. Med. Biol. 53: 35433549, 2008.

Zhou R.Y., Wang C., Xu W.D., Xie L.J.: Biological applications of terahertz technology based on nanomaterials and nanostructures. - Nanoscale 11: 3445-3457, 2019.

(C) The authors. This is an open access article distributed under the terms of the Creative Commons BY-NC-ND Licence. 